\title{
CLASSIFICAÇÃO DAS SUBSTÂNCIAS QUÍMICAS: UM CONCEITO POUCO EXPLORADO NA EDUCAÇÃO QUÍMICA
}

\author{
Cintia Maria Carneiro Franco Lima ${ }^{a}$ e José Luis P. B. Silva ${ }^{b, *,(1)}$ \\ aDepartamento de Química Orgânica, Instituto de Química, Universidade Federal da Bahia, 40170-115 Salvador - BA, Brasil \\ 'Departamento de Físico-Química, Instituto de Química, Universidade Federal da Bahia, 40170-115 Salvador - BA, Brasil
}

Recebido em 03/06/2020; aceito em 29/09/2020; publicado na web em 06/11/2020

\begin{abstract}
CLASSIFICATION OF CHEMICAL SUBSTANCES: A LITTLE-EXPLORED CONCEPT IN CHEMICAL EDUCATION. The classification of chemical substances is a concept little explored in Chemistry teaching literature and in Chemistry textbooks at higher and secondary levels. The aim of this paper is to discuss theoretically the importance and contributions of this concept for teaching and learning Chemistry. The History of Chemistry reveals that the chemical criteria for classifying materials came up with the modern concepts of chemical element and chemical reaction, which gave rise to the notion of chemical similarity. Later, such similarity was related to molecular structure through functional groups. The classes of substances are related throughout chemical reactions, during which substances of given classes are transformed into substances of other classes, constituting a wide network. The classification of chemical substances can contribute to the intellectual development of Chemistry students, in order to study it, it becomes necessary to understand its theoretical foundation, as well as its characteristics of objectivity, completeness, simplicity and prediction. In this sense, one can contribute to the stimulation of perception, attention and abstraction that are typical of the chemical ways of thinking and communicating necessary for learning the chemical concepts linked to classification.
\end{abstract}

Keywords: classification of chemical substances; chemical similarity; chemical education.

\section{INTRODUÇÃO}

É consensual que a Química tem como fundamentos a composição e a transformação dos materiais. ${ }^{1}$ Independentemente da ausência de entendimento acerca da prioridade de um conceito sobre o outro — "Uma reação química é definida pela transformação de certas substâncias, ou as substâncias são definidas por suas reações químicas características?"² — não resta dúvida de que os químicos operam com substâncias e reações químicas. Por isso, a Química compreende os materiais como compostos por substâncias químicas.

A quantidade de substâncias químicas é muito grande, da ordem dos milhões e tem crescido exponencialmente desde $1800 .{ }^{3}$ Embora diferentes, as substâncias guardam similaridades entre si, por meio das quais são agrupadas em uma quantidade de classes da ordem das dezenas, o que constitui uma espetacular economia cognitiva, pois pelas características de cada classe podemos saber os atributos mais importantes das substâncias pertencentes às mesmas.

De modo geral, uma classificação válida e testável discrimina as distintas partes do conhecimento, provendo-lhe estrutura, e se caracteriza por: (a) fundamentação teórica, a partir da qual as classes são definidas e sua ordem é estabelecida; (b) objetividade, no sentido da generalização conceitual promovida pelas classes ser limitada por critérios de classificação explícitos, que possibilitem a qualquer um utilizá-los para classificar novos casos que se apresentem; (c) completeza, por incluir todos os possíveis casos de modo unívoco; (d) simplicidade, por reduzir a quantidade de informação necessária ao processo de sua elaboração; (e) predição de novos casos possíveis e de correlações entre variáveis não empregadas no processo de classificação. $^{4}$

Como é possível notar, a compreensão de um sistema de classificação envolve conhecimento amplo e profundo dos casos que abarca e do campo de estudos no qual se insere. Logo, a classificação das substâncias químicas requer conhecimento amplo e profundo

*e-mail: joseluis@ufba.br das substâncias químicas e da Química, podendo contribuir para seu ensino e sua aprendizagem.

As substâncias são classificadas em termos de sua composição química e possibilidades de transformação química. ${ }^{2}$ As outras propriedades dos materiais são, então, explicadas com base nas classes de suas substâncias componentes. Desse modo, os conhecimentos químicos estabeleceram um diferente ponto de vista a partir do qual admirar o aspecto material do mundo. Consequentemente, os conteúdos curriculares de Química podem contribuir para o desenvolvimento de competências de várias ordens: cognitivas, sociais etc.

Entretanto, a classificação das substâncias químicas é um tema pouco estudado na área de Educação Química, conforme verificado por buscas na literatura nacional e internacional. São encontrados trabalhos sobre: classificação periódica dos elementos; ${ }^{5}$ métodos históricos de classificação de substâncias; ${ }^{6}$ relações entre classes de substâncias e seu emprego social ${ }^{7}$ classificação da matéria de acordo com os estados de agregação; ${ }^{8}$ ensino da nomenclatura química, ${ }^{9}$ sem que se estendam à discussão conceitual das classes das substâncias químicas.

Uma exceção é o trabalho de Santos, Ribeiro e Labarca, ${ }^{10}$ no qual são discutidos vários aspectos das classificações, em geral, e das classificações químicas em particular, porém, com maior foco na classificação periódica dos elementos.

Os materiais didáticos também deixam a desejar maior discussão sobre este importante conceito. Em livros didáticos de Química Geral empregados nos Cursos de Química, ${ }^{11}$ o verbo classificar é usado ao longo do texto e em relação a vários itens: materiais, elementos químicos, átomos, ácidos, entre outros. As substâncias também são classificadas como simples e compostas, orgânicas e inorgânicas, solúveis e insolúveis, entre outros tipos. Nessas obras, a ênfase recai sobre os grupos funcionais das moléculas dos compostos orgânicos, como característica distintiva, sem maior discussão. De modo geral, o termo classe é empregado, sem qualquer conceituação química, o que contribui para a adoção de um significado vago e sem justificativa. 
Poder-se-ia imaginar que a classificação das substâncias químicas fosse tratada no Ensino Médio. Nesse ponto, porém, todos os 6 (seis) livros didáticos de Química para o Ensino Médio aprovados pelo PNLD2018 ${ }^{12}$ não diferem dos seus congêneres do Ensino Superior. Em algumas obras, classe de substância é considerada como sinônimo de função química, que é o conceito destacado. Em outros livros didáticos, as classes são subordinadas à discussão sobre nomenclatura química.

Seja no Ensino Superior seja no Ensino Médio, não há discussão didática e sistemática dos critérios de classificação das substâncias, tornando-se necessária maior exploração desse conceito.

De modo geral, o que se pode notar é a pouca importância atribuída à classificação das substâncias químicas na Educação Química. Talvez por isso, o estudo das funções químicas esteja associado à memorização sem significado. ${ }^{13}$

Em vista do exposto, o objetivo deste trabalho é discutir teoricamente a importância e as contribuições do conceito de classificação das substâncias químicas para o ensino e a aprendizagem da Química.

A lógica que presidiu a resolução do problema proposto, foi: partir do geral (teoria das classificações) para o particular (classificações das substâncias químicas) e, então, apresentar as implicações para a Educação Química. Por isso, a próxima seção apresenta o referencial teórico adotado para o ato de classificar e as classificações em geral, seguida da metodologia que dele decorre e foi empregada na pesquisa das características das classificações das substâncias ao longo da História, os resultados alcançados e sua discussão e, por fim, as contribuições para a Educação Química e a conclusão.

\section{SOBRE AS CLASSIFICAÇÕES EM GERAL}

Ao longo de sua história, os seres humanos desenvolveram a capacidade de classificar os elementos do mundo e, entre estes, os materiais com os quais interagem. Classificar consiste em elaborar classes e atribuir elementos - objetos, situações, eventos - às classes elaboradas. O resultado desse processo de classificação é uma classificação ou sistema classificatório. ${ }^{4}$

Classificar é um processo complexo. A elaboração de uma classe é realizada pela abstração (separação) das características comuns de um conjunto de elementos — objetos, situações, eventos — para juntá-las novamente (e somente essas características) numa nova totalidade, que é a classe. Por exemplo, materiais cuja característica é ser empregado na construção de imóveis, tais como: cimento, areia, madeira natural e/ou serrada, portas, fechaduras etc., são classificados como materiais de construção; frutas, legumes e cereais comestíveis pertencem à classe dos alimentos; os materiais empregados no combate às enfermidades são denominados medicamentos e assim por diante. Como se pode notar, cada classe possui uma expressão materiais de construção, alimentos, medicamentos - que pode ser uma palavra ou conjunto de palavras de língua natural, mas também pode ser um conjunto de gestos de Libras, um desenho, uma nota musical, um símbolo químico, um símbolo matemático etc.

Abstrair consiste em separar uma parte de um todo, por um processo de pensamento, para considerá-la independentemente das demais partes e do todo. ${ }^{14}$ Desse modo, a classe também se caracteriza pela ausência dos aspectos não comuns aos casos classificados e se constitui numa abstração em relação aos casos específicos nela incluídos. Por exemplo, a classe das substâncias químicas inclui todos os materiais que podem ser considerados puros. ${ }^{15}$ A pureza de um material independe da massa molar, da densidade, das temperaturas de fusão e de ebulição, da solubilidade, entre outros aspectos não considerados na formação da classe cuja denominação é substância química.
Quando um elemento novo se apresenta ao ser humano, a percepção das suas características possibilita a comparação com as características definidoras das várias classes existentes e sua atribuição a uma ou mais classes. ${ }^{16}$

Uma classificação se inicia com a ideia de que o mundo, ou parte dele, é constituído por (a) elementos com identidade própria e que (b) alguns desses elementos guardam similaridade entre si. Isso constitui uma visão do mundo que faz parte da cultura humana, ou seja: essas ideias não são evidentes, mas, elaboradas teoricamente na relação dos seres humanos com a experiência empírica do mundo. São os pressupostos teóricos de qualquer classificação, pois é a partir da constatação da similaridade dos elementos da nossa vivência diária que os classificamos, conforme exemplificado acima.

A seleção das características distintivas de cada classe pode se dar de vários modos e foge ao escopo deste trabalho discuti-los. No que concerne ao nosso objetivo, é importante notar que todos esses modos recorrem a atividades psicológicas tais como: percepção, atenção, memória, análise, raciocínio lógico, linguagem. Frente a um conjunto de elementos do mundo - objetos ou situações ou eventos - o ser humano busca identificar aquilo que constitui padrões ${ }^{4,17} \mathrm{e}$ estabelece a similaridade entre os elementos. Para tanto, deve estar com a atenção voltada para a atividade analítica, ou seja, deve estar com a percepção direcionada aos traços característicos de cada caso, memorizando-os para efeito de comparação, com o objetivo de decidir o que há de comum entre todos, estabelecendo sua semelhança. Tais traços comuns precisam ser relacionados de modo a formar um sistema que representa sua síntese: a classe.

Esse processo de abstração e síntese reduz a quantidade de informação necessária à identificação dos elementos do mundo, ao tempo que os trata de modo mais geral, constituindo uma economia cognitiva.

Conforme suas características distintivas, as classes podem ser mais ou menos abrangentes e pode ser (ou não) estabelecida uma hierarquia na classificação. Por exemplo, pode-se descrever e explicar o comportamento químico da matéria de acordo com modelos baseados no tamanho presumido dos entes materiais pertencentes a cada classe e que formam níveis hierárquicos: macroscópico $>$ mesoscópico $>$ multiparticulado $>$ supramolecular $>$ molecular $>$ subatômico. ${ }^{18}$ No entanto, as classificações das substâncias químicas não formam hierarquias, conforme discutido adiante.

As características dos elementos da classe definem e limitam sua extensão, posto que só podem ser incluídos na classe os elementos que as exibem. É o que se denomina de objetividade da classe. ${ }^{4}$ Para que qualquer ser humano possa entender a definição da classe e classificar novos casos que se apresentem, tais características devem ser formuladas da forma mais explícita possível.

A completeza de uma classe, no sentido de incluir todos os possíveis elementos de modo unívoco, depende das expressões das características não serem ambíguas, se possível, ou terem sua ambiguidade reduzida ao mínimo. ${ }^{4,10}$

O conhecimento de uma classificação possibilita prever outros elementos que possam ser incluídos nas suas classes e sua correlação com variáveis não empregadas no processo de classificação. ${ }^{4}$

Entendemos que o processo de classificação descrito acima pode contribuir em muito para o ensino e a aprendizagem. ${ }^{10}$ Em primeiro lugar, devemos notar que há uma correspondência entre a elaboração de uma classe e a elaboração de um conceito (ou significado): ${ }^{19}$ todo conceito é geral e abarca um conjunto de casos — objetos ou situações ou eventos - similarmente caracterizados, de modo que, a cada classe corresponde um conceito. Portanto, ao ensino e à aprendizagem de uma classificação corresponde o ensino e a aprendizagem de um conjunto de conceitos que formam um sistema. 
A aprendizagem de um conceito vinculado a uma classe pode ocorrer de dois modos: pela experimentação direta dos casos que possibilitem elaborá-lo ou, indiretamente, por experiências relatadas por outrem, a exemplo do que ocorre no ensino de grande parte dos conhecimentos adquiridos pelos seres humanos nas escolas. Ora, o modo como um conceito é pensado não é o mesmo pelo qual é comunicado: o pensamento age na interioridade do sujeito, ao passo que a comunicação age publicamente, entre sujeitos.

No ensino, o/a docente ou o material de ensino comunica o conceito pensado e armazenado na memória coletiva e, na passagem do pensamento para a comunicação, o conceito precisa ser expresso por meio de um termo ou expressão que o designa, seja esta sonora, seja gráfica ou pictórica, em língua natural, simbologia musical, matemática ou química, ou outro modo qualquer que sirva à comunicação entre humanos. A relação entre expressão e conceito é estabelecida por algum tipo de convenção cultural, de modo que, expressão é a parte material do conceito, o qual é o conteúdo da expressão. ${ }^{20}$ É o que ocorre com a expressão substância química, que se refere a determinados tipos de materiais. Para explicitar o conteúdo desta expressão precisamos empregar outras expressões que explicitem a característica por meio da qual um material é incluído nesta classe, qual seja: ser puro.

Então, a aprendizagem pode ser iniciada, tanto pela experiência com os elementos de uma classe quanto pela expressão da classe, que é a mesma do conceito, ou por ambas, simultaneamente. Consideremos um exemplo da aprendizagem pela experiência direta. Costumeiramente, quando um estudante ouve a expressão substância química pela primeira vez, é numa sala de aula de Química (ou de Ciências Naturais) e em relação a algum material. Ao tomar conhecimento que se trata de material puro, pode associar a pureza química à ideia de limpeza aprendida com as noções de higiene, em sua experiência direta. Quando o termo substância passa a ser constantemente empregado durante as aulas, cria-se um problema: se o que faz com que materiais tão diferentes quanto vários sólidos e líquidos citados sejam substâncias é sua pureza, como purificálos? A resposta a essa questão pode explicar o significado da pureza química, que é um conceito teórico e, finalmente, do critério químico para classificar um material como substância. ${ }^{15}$

Da relação da palavra com um exemplar da classe para a relação com vários exemplares e ao emprego da palavra na ausência de qualquer exemplar, a criança realiza um longo trabalho psicológico que vai numa abstração crescente, afastando-se da concretude da experiência, a qual fica retida na memória. Essa abstração que acompanha a formação de uma classe torna-a mais geral que os casos a partir dos quais foi formada: a classe não é nenhum exemplar, nem é o conjunto dos exemplares que podem ser abarcados pelos critérios que a constituem. Entretanto, refere-se tanto a um exemplar quanto ao seu conjunto. Em resumo, a classificação é um processo de abstração e generalização. ${ }^{19,21} \mathrm{O}$ mesmo processo ocorre com adultos, porém de modo mais rápido, em vista da experiência acumulada de lidar com situações em que novos conhecimentos lhes são apresentados.

A classificação, como todo processo de elaboração conceitual, envolve pensamento e linguagem e, por isso, é um processo psicolinguístico. A etapa da verbalização é extremamente importante para que o ser humano tome consciência do conceito e condição para a comunicação necessária à avaliação da aprendizagem. Compreender um conceito é bem diferente de explicá-lo. Ao elaborar uma explicação verbal, o indivíduo transforma os significados compreendidos em palavras. A escolha dessas palavras - que expressam outros conceitos — e sua organização sistemática têm por objetivo externar o pensamento do indivíduo do melhor modo possível e são influenciadas pelos modos de compreensão e aprendizagem do conceito que está sendo expresso. Essas atividades — escolha e organização de palavras para explicar um conceito - envolvem muita reflexão e fazem que haja um aprofundamento da compreensão do conceito, sua melhor fixação na memória, estabelecendo a possibilidade de sua externalização verbal e da justificativa verbal do seu emprego. Tais atividades são consideradas como evidências da elaboração e consciência do conceito. ${ }^{16,19,21}$

Conforme mencionado acima, cada conceito tem uma história psicológica que parte de uma percepção do concreto para a abstração, a qual é empregada na explicação dos casos concretos que lhe serviram de ponto de partida, podendo vir a incluir outros casos. Porém, como conceitos fazem parte da cultura, também são históricos no sentido de que nascem para solucionar problemas e se desenvolvem ao serem empregados na solução de outros mais que se apresentam à medida que o meio cultural sofre modificações. ${ }^{16,19}$ Desse modo, é de esperar que as características utilizadas como critérios para a classificação dos materiais, em geral, e das substâncias químicas, em particular, tenham se modificado ao longo do tempo, em função das alterações contextuais e das contribuições teóricas e/ou empíricas elaboradas pelos diversos atores envolvidos. Por isso, a História da Química pode contribuir para esclarecer o movimento conceitual da classificação das substâncias químicas.

O trabalho de articulação entre o pensamento e a linguagem que possibilita a formação psicológica de uma classe (ou conceito, em termos gerais), assim como a explicação de seu significado e de seus usos ampliam a capacidade de abstração, sistematização e generalização do sujeito e, desse modo, também ampliam sua conscientização e sua capacidade de se relacionar com o mundo sem necessidade de recorrer aos exemplares concretos de que o mundo é formado. Em suma: é um processo de desenvolvimento intelectual. Cabe aos docentes estimularem tais atividades para facilitar a aprendizagem do conceito em foco.

Ao conscientizar-se das características que possibilitam classificar algum elemento do mundo, por exemplo: os materiais, o sujeito pode falar dos materiais e objetos materiais de modo mais crítico e preciso, reduzindo a ambiguidade na comunicação. A aprendizagem do processo de classificação dos materiais possibilita o processo psicológico de sua transferência para outros elementos do mundo.

Portanto, a aprendizagem da classificação dos materiais, em geral - e, como veremos, da classificação química das substâncias, em particular — pode conduzir ao desenvolvimento intelectual dos estudantes de Química (e outros) e, desse modo, possibilitar outra compreensão do mundo material que os rodeia. Cabe aos professores dirigir as atividades de ensino no sentido de que isso aconteça.

\section{METODOLOGIA}

Adotando como premissa que todo conceito é histórico, entendemos que a História da Química pode tornar explícitas as características definidoras das classes de substâncias químicas, razão pela qual buscamos identificá-las por meio de uma análise temática descritiva do conteúdo ${ }^{22}$ de fontes históricas.

$\mathrm{Na}$ etapa de pré-análise selecionamos alguns textos clássicos de História da Química, ${ }^{23}$ por serem fontes de informação públicas, com credibilidade na literatura e acessíveis em bibliotecas ou pela rede mundial de computadores. Para obter maior detalhe e esclarecimento das contribuições mais importantes, as quais mudaram os rumos da Química do século XIX, recorremos a fontes primárias.. ${ }^{24}$ Outras fontes secundárias de História da Química foram adicionadas posteriormente para complementar e/ou esclarecer os conceitos em discussão.

Orientados pela noção de classificação apresentada na seção anterior, buscamos identificar as diferentes características que deram origem às várias classificações das substâncias. Para tanto, foram 
recortados trechos dos textos históricos que expressavam a própria ideia de classificação - por exemplo: trechos contendo os termos classificação, classe, tipo - e critérios empregados para classificação, tais como: procedência do material, uso, propriedades físicas e similaridade química baseada na composição e na estrutura molecular.

Os dados resultantes dessa análise foram agrupados em dois conjuntos: antecedentes da classificação química das substâncias e classificação química das substâncias propriamente dita. $\mathrm{O}$ critério de divisão dos dados é a emergência do conceito moderno de elemento químico e da composição elementar como característica distintiva das classes de substâncias. ${ }^{24} \mathrm{O}$ segundo conjunto foi subdividido durante o processo de escrita com a intenção de tornar a exposição mais clara. Os resultados são apresentados na seção seguinte.

\section{RESULTADOS E DISCUSSÃO}

\section{Classificação química dos materiais: antecedentes}

Precisar quando os seres humanos começaram a transformar produtos naturais para seu uso é uma tarefa impossível. A elaboração de utensílios de madeira, de pedra, de peles etc., faz parte da préhistória do homem. O domínio do fogo foi, certamente, um passo decisivo para ampliação das possibilidades de transformação dos materiais. Tais práticas foram diversificadas e desenvolvidas ao longo dos séculos, articulando-se com ideias teóricas acerca da matéria e compondo um conjunto de conhecimentos sobre os quais veio se erigir a atividade química moderna. Desse modo, a Química recebeu heranças da Alquimia, das práticas médicas e das tecnologias metalúrgicas, cerâmicas, de vidros e outros tipos de materiais. ${ }^{25}$

As classificações dos materiais desenvolveram-se par a par com as atividades humanas, segundo os mais variados critérios. De acordo com a procedência, os materiais eram (e ainda são) classificados como minerais, vegetais e animais. Tomando a aparência e o uso como características distintivas, várias classes foram estabelecidas, por exemplo: metais, ligas, vidros, cerâmicas, pigmentos, medicamentos etc.

Critérios de ordem operacional e/ou propriedades físicas também foram empregados desde muito tempo. Por exemplo, na Alquimia do oriente próximo dos séculos VIII ao X, os minerais foram subdivididos nas classes dos espíritos (que vaporizavam por aquecimento); corpos (não voláteis: metais); vitríolos (cristalinos brilhantes, vítreos); boratos (cristais brancos); pedras e sais. ${ }^{26} \mathrm{O}$ processo que levou os diversos tipos de atividades humanas com a matéria ao estado de constituição da Química como uma ciência foi demorado e, de acordo com Debus, ${ }^{27}$ estendeu-se do século XVI ao XVIII. Durante esse período, os critérios de classificação dos materiais passaram de propriedades sensíveis, tais como: cor, odor, sabor, estados de agregação e forma cristalina, a critérios químicos, a saber, composição e reatividade. ${ }^{28}$ No final do século XVIII, o trabalho de sistematização da nomenclatura química realizado por Guyton de Morveau, Lavoisier, Berthollet e Fourcroy contribuiu decisivamente para o estabelecimento de critérios químicos para a classificação dos materiais. ${ }^{29}$

O Tratado Elementar de Química de Lavoisier, publicado em 1789 , empregou a nova nomenclatura e foi prontamente traduzido para várias línguas europeias, produzindo larga aceitação e disseminação das novas ideias. ${ }^{24} \mathrm{~A}$ relação entre nomenclatura química e classificação química dos materiais é exposta logo nas primeiras linhas do Discurso Preliminar do Tratado:

O meu objetivo quando comecei esta Obra era apenas desenvolver melhor a Memória que li na sessão pública da Academia das Ciências no mês de abril de 1787, sobre a necessidade de reformar e aperfeiçoar a Nomenclatura da Química.

[...] E, realmente, enquanto eu acreditava que me ocupava da Nomenclatura, e tinha por objetivo apenas aperfeiçoar a linguagem da Química, a minha Obra se transformou imperceptivelmente nas minhas mãos, sem que fosse possível evitar, em um Tratado Elementar de Química.

A impossibilidade de isolar a nomenclatura da ciência e a ciência da nomenclatura está relacionada com o fato de que toda ciência física é formada de três coisas: a série de fatos que a constituem, as ideias que a lembram, as palavras que as exprimem. A palavra deve fazer nascer a ideia, a ideia deve representar o fato; fazem-se três impressões de um mesmo selo e, como são as palavras que conservam e transmitem as ideias, disso resulta que não se pode melhorar a linguagem sem aperfeiçoar a ciência, nem a ciência sem a linguagem, e que por mais certos que fossem os fatos, por mais justas que fossem as ideias geradas, elas ainda só transmitiriam impressões falsas, se não tivéssemos expressões exatas para designá-las. $^{24}$

A expressão química (a palavra), segundo Lavoisier, deve remeter às características químicas dos materiais (a ideia) - a composição da substância e/ou sua reatividade - as quais representam os fatos químicos, uma vez que são observados experimentalmente. Um exemplo é a denominação oxigênio para "a base da porção respirável do ar", a qual deriva "de duas palavras gregas: $\varepsilon \xi \nu \varphi$, ácido, e $\gamma \varepsilon \imath v o \mu \alpha \mathrm{l}$, eu engendro, porque de fato uma das propriedades mais gerais dessa base é formar ácidos com a maior parte das substâncias". ${ }^{24}$

Lavoisier $^{24}$ explica que as classes de substâncias compostas receberam denominações que buscam lembrar "a propriedade comum a um grande número de indivíduos" e que, ao escolher as denominações dos materiais, "fizemos de tudo para que exprimisse a propriedade mais geral, a mais característica das substâncias". Assim, a classe dos elementos químicos ou substâncias simples abarcava as substâncias que não podiam ser decompostas pelos métodos até então conhecidos. $\mathrm{O}$ fato de uma substância não reagir às ações que visam decompô-la é, também, uma característica do material e aquela que distingue as substâncias simples das compostas.

Em consequência, substâncias compostas são aquelas que podem ser decompostas formando substâncias simples. A determinação da composição de um material consiste em sucessivos processos de decomposição até alcançar "o último termo a que chega a análise". ${ }^{24}$

Seguindo os princípios estabelecidos por Lavoisier, o Tratado comenta diversas classes de substâncias, por exemplo:

Ácidos: formada pelos produtos da combinação de substâncias com oxigênio. De acordo com Lavoisier, todos os ácidos possuem oxigênio em sua composição (ver explicação do termo oxigênio, acima).

Óxidos: compostos que também contêm oxigênio em sua composição, porém, em um grau menor que os ácidos.

Substâncias combustíveis: aquelas que têm afinidade pelo oxigênio e, portanto, participam de reações de combustão.

A obra de Lavoisier também traz denominações de classes estabelecidas por critérios não químicos, a exemplo de substâncias metálicas, pedras de diversos tipos, vitrificações, fluidos aeriformes, licores e terras de diversos tipos. Tal fato é compreensível, não só pela força da classificação tradicional, mas também por ser um trabalho que empregava uma nova nomenclatura e uma nova conceituação, apresentando, ainda, amplitude reduzida. Entretanto, estavam lançadas as bases para o emprego dos critérios químicos na classificação das substâncias. 
No início do século XIX, sob a influência dos trabalhos de Lavoisier e Davy, Berzelius ${ }^{30}$ propôs uma nova classificação e sua correspondente nomenclatura, com base em várias características das substâncias:

Ponderáveis e imponderáveis, caracterizadas por “obedecer à lei da gravitação" ou não, respectivamente.

As substâncias ponderáveis foram caracterizadas de dois modos não excludentes: de acordo com serem decomponíveis ou não (substâncias compostas ou simples) e de acordo com o polo elétrico da pilha para o qual se deslocava - positivo ou negativo durante sua decomposição eletrolítica (substâncias eletropositivas ou eletronegativas, respectivamente).

As substâncias compostas se dividiam em inorgânicas (ou não orgânicas) e orgânicas: A "principal diferença entre essas duas classes consiste em que a primeira contém apenas combinações binárias [...], enquanto que a última contém sempre combinações ternárias, quaternárias etc.". (Combinações ternárias e superiores de substâncias inorgânicas eram entendidas como resultantes de duas ou mais combinações binárias.) Berzelius também admitia que os compostos orgânicos tinham um modo de produção específico e diferente daqueles dos compostos inorgânicos.

As substâncias inorgânicas eram classificadas como: óxidos; ácidos; combustíveis; combinações de óxidos com ácidos; combinações de óxidos com óxidos; combinações de óxidos com combustíveis. Note-se o emprego da reatividade como característica distintiva dessas classes. Os compostos de cada classe eram subclassificados, também conforme suas propriedades químicas específicas.

As substâncias orgânicas eram classificadas conforme a procedência em vegetais, animais e substâncias decorrentes da sua degradação.

\section{A similaridade química como característica classificatória das substâncias}

O critério geral atualmente empregado para a classificação das substâncias químicas é sua similaridade química, definida por meio do comportamento das substâncias na presença de algum agente: calor, luz, eletricidade, outra(s) substância(s) etc., comportamento também denominado propriedade química ou reação química. Portanto, "duas substâncias são quimicamente similares se cada uma delas reagir sob as mesmas condições para formar produtos de uma classe comum de substâncias" e "duas substâncias pertencem à mesma classe se forem quimicamente similares".31

As definições de classe de substâncias químicas e de similaridade química sugerem uma circularidade (não viciosa), uma vez que uma depende do conceito da outra. Para romper esta mútua dependência, adotamos a classe das substâncias químicas elementares como ponto de partida para uma classificação das substâncias e definimos similaridade química de modo mais específico: "duas substâncias são quimicamente similares se podem ser decompostas nas mesmas substâncias elementares"31 ou, de modo um pouco mais amplo, duas substâncias são quimicamente similares se podem ser decompostas em, ao menos, uma substância elementar comum.

\section{A classe das substâncias elementares}

A classe dos elementos químicos — ou substâncias elementares ganhou muitos novos casos após a publicação do Tratado de Lavoisier, chegando aos atuais 118 elementos, dos quais 90 são naturais e os demais, fabricados em laboratório. Essa classe foi organizada na Tabela Periódica dos Elementos. ${ }^{32}$ Suas primeiras versões foram publicadas em 1869, por Meyer e Mendeleev, independentemente, como síntese de um coletivo esforço de organização ao longo do século XIX. Os elementos foram organizados em ordem crescente das massas atômicas, formando um quadro de um modo tal que suas propriedades apresentavam repetição a cada nova linha, estabelecendo o que se denominou de lei periódica. Em 1913-1914, Henry Moseley apresentou a tabela dos elementos químicos em ordem crescente de número atômico. ${ }^{33}$

É importante lembrar que tal sistematização foi inicialmente elaborada com base nos conhecimentos acerca das substâncias químicas antes que a teoria atômica tivesse aceitação consensual na comunidade dos químicos e fosse empregada na interpretação da lei periódica que constitui o princípio sistematizador da tabela. Ou seja, o critério para a classificação de uma substância como elementar ou, sua similaridade química, era o mesmo empregado por Lavoisier: a impossibilidade de decomposição do material pelos métodos conhecidos.

A partir da definição da classe das substâncias elementares foram criadas várias outras classes de substâncias, tais como: hidrocarbonetos (compostos contendo apenas carbono e hidrogênio), ${ }^{34}$ óxidos (compostos contendo oxigênio como como elemento eletronegativo), ${ }^{35}$ hidretos (compostos contendo halogênio como elemento eletronegativo) ${ }^{35}$ etc. Em todos esses casos, duas substâncias pertencem à mesma classe se reagem (decompõem-se) nas mesmas condições, formando, ao menos, uma substância elementar comum.

\section{As classes das substâncias compostas}

As primeiras classes de substâncias compostas foram obtidas pela similaridade em termos de decomposição elementar. A partir dessas classes, outras puderam ser estabelecidas considerando-se que duas substâncias pertencem à mesma classe se cada substância reage em condições aproximadamente iguais, mas de modo independente, para formar (ao menos) uma substância que pertença a uma outra classe de substâncias, que é comum aos produtos das duas reações. ${ }^{31}$

Consideremos o caso de dois óxidos diferentes que reagem com água de modo que cada óxido forme um composto aparentemente diferente. Porém, verifica-se que, ambos os produtos reagem com solução de tornassol, dando-lhe coloração vermelha, característica (similaridade química) que define a classe dos ácidos. Então, a partir de uma classe de substâncias cuja similaridade química consiste em serem decompostas em oxigênio, é estabelecida outra classe de substâncias definida pela similaridade química de reagir com solução de tornassol, formando um composto vermelho. Desse modo, foram estabelecidas relações entre duas classes de substâncias: óxidos e ácidos. ${ }^{36}$

Contudo, óxidos também podem reagir com água para formar substâncias que reagem com solução de tornassol, dando-lhe coloração azul, característica que define os hidróxidos. ${ }^{36}$ Uma vez que os óxidos reagem em condições similares para formar substâncias de classes diferentes, devem formar subclasses diferentes de substâncias: óxidos ácidos e óxidos básicos. Desse modo, foram estabelecidas relações entre três classes de substâncias: óxidos, ácidos e hidróxidos e duas subclasses de óxidos.

Relações entre outras classes de substâncias foram estabelecidas por outras similaridades químicas: haletos podem formar ácidos e podem ser formados a partir de óxidos; hidrocarbonetos podem formar haletos, ácidos e nitrocompostos; ácidos podem ser usados para produzir álcoois, nitrocompostos e ésteres, ${ }^{36,37} \mathrm{e}$ assim por diante. Desse modo, o conjunto das classes de substâncias constitui uma grande rede - com cada classe em um nó ligado a outros por meio de reações químicas - conforme apresentado na Figura 1.

Não nos alongaremos na apresentação das denominações das classes das substâncias químicas, pois isso foge ao nosso objetivo neste trabalho. O que nos interessa é explicitar o critério que faz que uma substância possa ser inserida em uma (ou mais de uma) classe, qual seja: a similaridade química. 


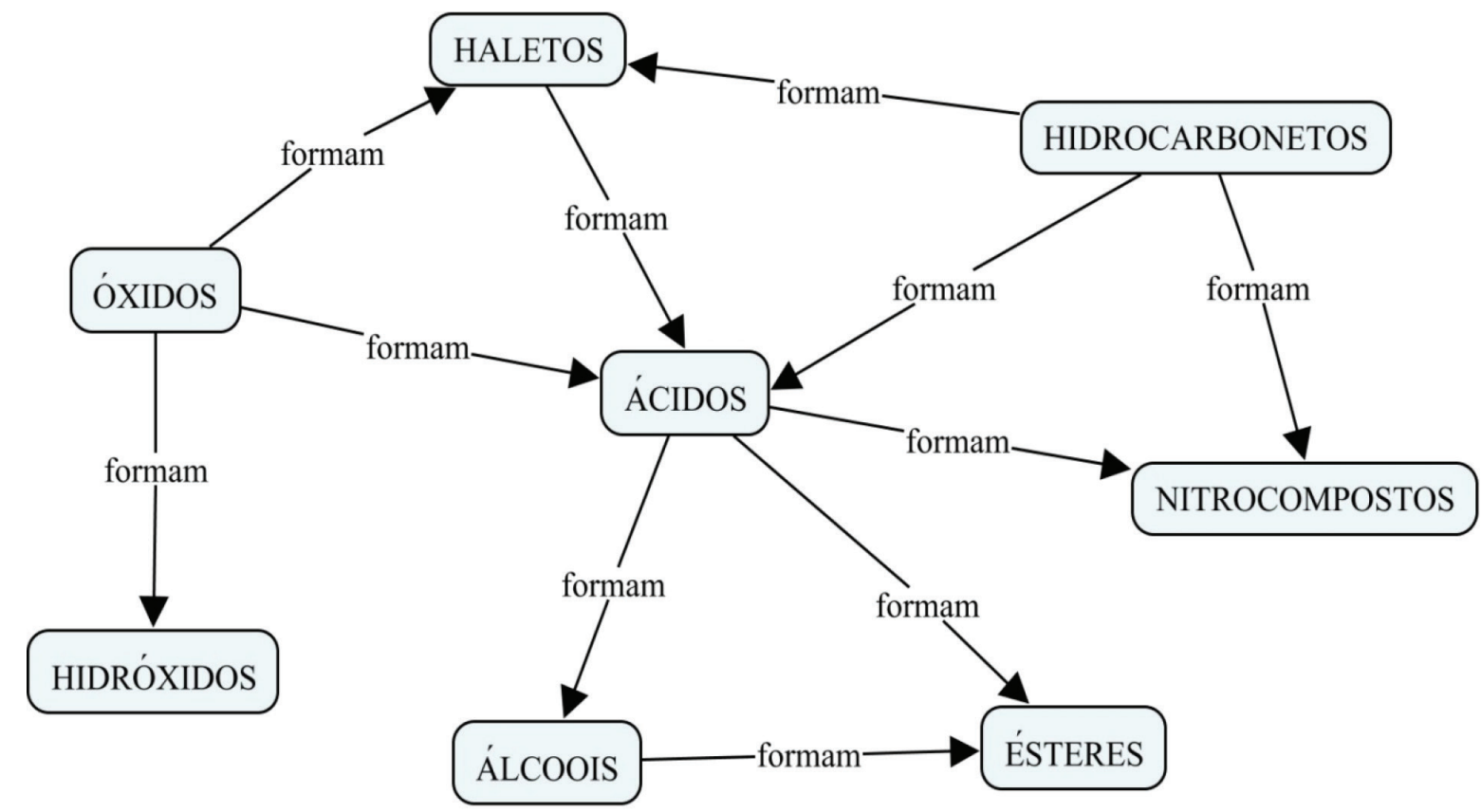

Figura 1. Rede de relações entre classes de substâncias químicas

\section{O grupo funcional como característica classificatória das substâncias}

No início do século XIX, a composição das substâncias recebeu explicações em termos de átomos dos elementos químicos e desenvolveu-se a ideia de fórmula química empírica (para as quais Berzelius muito contribuiu), a qual indicava as quantidades de átomos de cada elemento químico presentes na molécula, de acordo com o entendimento da época. ${ }^{38}$

Na primeira metade do século XIX, verificou-se que algumas substâncias apresentavam a mesma composição elementar, mas formavam substâncias de classes diferentes quando reagiam nas mesmas condições. De início, os químicos pensaram que tivesse havido erros nas análises dos produtos das reações, mas, ao constatar sua exatidão, tiveram que admitir a veracidade dos fatos. Tais compostos foram denominados isômeros por Berzelius, no sentido de que "os mesmos elementos, unidos no mesmo número, mas de modo diferentes (talvez numa disposição dos átomos), produzem compostos de propriedades e formas diferentes". ${ }^{39}$ Foi o primeiro passo para o desenvolvimento do conceito de estrutura molecular, o qual derivou das noções de radicais e tipos constituintes das moléculas.

O termo radical remonta a Guyton de Morveau, segundo Lavoisier, ${ }^{24}$ e significava toda substância que reagia com oxigênio para formar um ácido. No século XIX, o termo radical se vinculou ao estudo da nascente Química Orgânica, no sentido moderno do termo, qual seja, de grupos atômicos que se mantinham inalterados ao longo de um conjunto de transformações químicas. Portanto, os radicais comportavam-se como "equivalentes orgânicos dos elementos inorgânicos tendo o mesmo tipo de individualidade e estabilidade que esses últimos". ${ }^{40}$

A teoria dos radicais foi a primeira tentativa de se explicar a reatividade das substâncias orgânicas. Os trabalhos de Liebig e Wöhler da década de 1830 contribuíram decisivamente para o estabelecimento e a difusão desta teoria, no que foram seguidos por outros químicos importantes da época, a exemplo de Dumas, Bunsen e Berzelius. ${ }^{40,41}$ As substâncias podiam ser classificadas conforme os radicais que contivessem.

No mesmo período, Laurent desenvolveu a noção de reações de substituição e sugeriu um modelo tridimensional para as moléculas, no qual tomavam parte grupamentos atômicos denominados núcleos, similares aos radicais. Dumas aceitou as reações de substituição, porém, divergiu da proposta dos núcleos moleculares de Laurent e introduziu a noção de tipos, ou seja, substâncias que podiam ter átomos substituídos "sem alterar sua natureza original". ${ }^{40}$

As teorias dos radicais e dos tipos podem ser vistas como propostas distintas importantes e úteis para a explicação da formação de compostos orgânicos nos meados do século XIX. Ambas foram finalmente reorganizadas e reconciliadas para formar a base da moderna teoria da valência, ${ }^{30}$ na qual, a valência era entendida como "poder de combinação" de um átomo. ${ }^{40}$

Kekulé, porém, baseou-se na ideia de que os átomos dos elementos se encontram interligados na molécula e, sem se prender aos conceitos anteriores de radicais ou tipos, estabeleceu o átomo de carbono como tetravalente e elaborou a noção de cadeia carbônica. Couper contribuiu decisivamente para a elaboração da teoria estrutural, inclusive, na elaboração das fórmulas estruturais, muito parecidas com as atuais. ${ }^{40}$

Fundamentado nos trabalhos de Couper, Butlerov ${ }^{40}$ formulou o conceito de estrutura molecular, como o "modo de mútua ligação dos átomos em uma molécula", cuja expressão seriam as fórmulas estruturais. Butlerov distinguiu a estrutura física das moléculas, desconhecida, da estrutura química, que seria dedutível dos produtos das reações químicas. Atualmente, considera-se que a fórmula estrutural "fornece informação sobre o modo que os átomos em uma molécula estão conectados e arranjados no espaço". ${ }^{42}$

A teoria estrutural herdou dos radicais e dos tipos a ideia de que durante uma reação química não ocorre, necessariamente, a transformação de toda a molécula, mas, de apenas uma parte da sua estrutura. Desse modo, a similaridade química foi associada à composição e à estrutura das moléculas, possibilitando a distinção e a classificação das substâncias isômeras, as quais teriam a mesma composição, porém, estruturas químicas diferentes.

A cada classe de substâncias corresponde um aspecto estrutural, denominado grupo funcional, entendido como um mesmo "átomo ou grupo de átomos que possuem propriedades químicas similares toda vez que ocorre em compostos diferentes". ${ }^{43}$ Como cada grupo funcional reage quimicamente de modo similar, a presença do grupo na molécula de uma substância pode ser usada como característica 
distintiva para a sua classificação. Cada grupo funcional tem uma composição e uma estrutura bem definidas.

O Quadro 1 apresenta várias classes de substâncias cujo critério de classificação é a existência do grupo funcional na molécula da substância.

Quadro 1. Classes de substâncias orgânicas e correspondentes grupos funcionais

\begin{tabular}{|cc|}
\hline Classe & Grupo funcional \\
\hline Aldeído & $-\mathrm{C}(=\mathrm{O}) \mathrm{H}$ \\
Éter & $-\mathrm{O}-$ \\
Amina & $-\mathrm{NH}_{2}$ \\
Ácido carboxílico & $-\mathrm{C}(=\mathrm{O}) \mathrm{OH}$ \\
\hline
\end{tabular}

O conceito de grupo funcional é comumente empregado em relação aos compostos orgânicos, porém, não há impedimento quanto ao seu emprego em compostos inorgânicos, ${ }^{43,44}$ nos quais também podem ser utilizados como critérios de classificação, conforme visto no Quadro 2.

Quadro 2. Classes de substâncias inorgânicas e correspondentes grupos funcionais

\begin{tabular}{|cc|}
\hline Classe & Grupo funcional \\
\hline Hidróxido & $-\mathrm{OH}$ \\
Haleto & $-\mathrm{X}(\mathrm{X}: \mathrm{F}, \mathrm{Cl}, \mathrm{Br}$ e I $)$ \\
Hidreto & $-\mathrm{H}$ \\
Peróxido & $-\mathrm{O}-\mathrm{O}-$ \\
\hline
\end{tabular}

Em suma: a similaridade química é o critério geral empregado para a classificação das substâncias químicas e, desdobra-se em dois critérios particulares: a composição química elementar e os grupos estruturais funcionais.

\section{CONTRIBUIÇÕES PARA A EDUCAÇÃo QUÍMICA}

Pelo exposto, notamos que a classificação de substâncias químicas é um conceito muito rico, uma vez que forma um sistema com vários outros conceitos: substância, substância simples, substância composta, composição química, reação química, fórmula empírica, fórmula estrutural, grupo funcional, estrutura química, além de todos os demais conceitos que se relacionam com os citados. Isso nos mostra que há necessidade de uma grande quantidade de conhecimento por parte dos estudantes para que a classificação das substâncias químicas possa ser aprendida de modo amplo e profundo. Portanto, nossa primeira proposição é que tal conceito seja ensinado por partes, ao longo de um processo didático que percorra trilhas do sistema conceitual ao qual pertence. Entendemos que há mais de um modo de percorrer esse sistema e a sugestão seguinte é apenas uma entre várias possíveis.

Em primeiro lugar, a aprendizagem do conceito de classe pode contribuir para aguçar a percepção de que o mundo é constituído por elementos que guardam similaridade entre si, formando padrões, e que por isso, podem ser tratados em conjunto. Tal noção é muito importante por ser o fundamento para a elaboração de conceitos e classes. Isso pode ser realizado por meio da discussão acerca da similaridade entre diversos materiais de uso corriqueiro - por exemplo: materiais de construção, alimentos, medicamentos seguida da discussão do conceito químico de substância para, então, se chegar à similaridade das substâncias.
Propomos a similaridade química como o fio condutor do ensino do conceito de classe de substâncias químicas. Considerando que os estudantes universitários possuam algum conhecimento anterior de Química, o ensino pode iniciar pelo levantamento das características empíricas (a) dos materiais e (b) das transformações de materiais conhecidas pelos estudantes. Segue-se a discussão das similaridades e das diferenças dos materiais, visando chegar à compreensão de quais características são importantes nessa classificação. Então, pode ser introduzida a noção teórica de composição dos materiais relacionada aos conceitos de substância, mistura e reação química e às técnicas empíricas de separação de substâncias.

A conjunção dos conceitos teóricos com a percepção sensível desenvolve a percepção e a atenção dos estudantes, possibilitandoos refletir sobre os dados empíricos com base nos novos elementos teóricos aprendidos. Estão criadas as condições para a apresentação do conceito de reação de decomposição.

Neste ponto, discutem-se as duas primeiras classes de substâncias baseadas na composição elementar — substâncias simples e compostas - as quais servirão para elaborar a própria noção de classe de substância a partir de: (a) a compreensão dos critérios de classificação (substâncias decomponíveis ou não decomponíveis); (b) que tais critérios se aplicam a vários materiais diferentes (discutir exemplos) e (c) que, por isso, a classe é uma generalização abstrata em relação aos materiais que classifica (mostrar que os exemplares das substâncias apresentam outras características além de serem decomponíveis ou não).

Simultaneamente, os estudantes são introduzidos na nomenclatura das classes das substâncias químicas e dos exemplares de cada classe, quais sejam: as substâncias químicas específicas. Não propomos a memorização da nomenclatura como objetivo do ensino, mas sim, como reconhecimento da indissociabilidade entre linguagem e conceito, baseado no fato de que a cada termo diferente corresponde um conceito diferente, conforme Lavoisier chamara a atenção há mais de 200 anos.

Uma vez que os estudantes tenham aprendido os conceitos de elemento químico e átomo, que se correspondem, ${ }^{45}$ torna-se possível reconhecer por similaridade quais substâncias são simples ou compostas pelo exame das suas fórmulas empíricas.

Nesse ponto do ensino, cabe uma discussão histórica das classificações materiais antecedentes, considerando os tipos de características (empíricas, pragmáticas etc.) que estabelecem cada classe, no sentido de aprofundar a compreensão dos conceitos de classe e classificação dos materiais.

Em seguida, trabalha-se o ensino de outros tipos de reações químicas diferentes da decomposição elementar para generalizar a noção de similaridade química e introduzir mais classes de substâncias, a exemplo de óxidos, haletos e hidróxidos.

Com o ensino dos conceitos de átomo e molécula, estrutura atômica e ligação química, abrem-se as portas para o ensino da estrutura molecular, da isomeria e das classes de substâncias que se baseiam na existência de grupamentos funcionais.

As relações entre similaridade química e estrutura molecular estabelecem um modo próprio de pensar da Química que contribui para o desenvolvimento do raciocínio lógico dos estudantes na medida em que vão compreendendo como são formadas as classes das substâncias.

Vale a pena notar que as classificações químicas dos materiais empregam critérios empíricos (p. ex.: estados de agregação: materiais sólidos, líquidos e gasosos), racionalistas (p. ex.: pureza química: substâncias (materiais puros) e misturas (materiais não puros)), históricos (p. ex.: metais e ametais) e pragmáticos (p. ex.: materiais orgânicos e inorgânicos, atualmente). É também importante notar que tais classificações não são excludentes, pois um material pode 
pertencer simultaneamente a mais de uma classe, por exemplo: uma substância metálica sólida inorgânica ou um aminoácido, cuja molécula possui grupamentos funcionais amino e ácido.

A cada nova etapa do ensino, o conhecimento acerca das classes de substâncias se amplia e dá uma noção de quão rica pode ser a descrição do mundo material. Tal ensino possibilita realizar, de modo explícito, um processo de elaboração conceitual complexo e sofisticado, no qual o entendimento químico acerca da matéria vai exigindo interpretações cada vez mais aprofundadas. A elaboração do sistema conceitual do qual as classes de substâncias fazem parte é um processo de desenvolvimento psicológico que pode ser transferido para outras áreas de conhecimento.

A classificação, como um dos modos do ser humano perceber e se situar no mundo, não se restringe aos materiais. Por exemplo: as classes das palavras e expressões linguísticas (substantivo, verbo etc.), os gêneros textuais (narração, argumentação etc.), os conjuntos de números (naturais, racionais etc.), os graus de equações matemáticas (primeiro, segundo etc.), os tipos de forças (gravitacional, elétrica etc.), os acidentes geográficos (cabo, baía etc.), as idades históricas (antiga, moderna etc.), as eras geológicas (paleozoica, mesozoica, etc.), as classes sociais (baixa, média etc.), as classes biológicas dos seres vivos (animais, vegetais etc.), as correntes filosóficas (idealista, materialista etc.) entre tantas outras possíveis classificações que os seres humanos inventaram. Por isso, a classificação química das substâncias pode ser ensinada de modo articulado com outras disciplinas.

A aprendizagem do sistema de conceitos da classificação das substâncias químicas torna possível a análise dos materiais com os quais os químicos lidam cotidianamente em termos mais profundos, levando a uma compreensão mais crítica dos materiais e substâncias em geral.

\section{CONCLUSÕES}

Os casos apresentados podem ser multiplicados e, conforme citado, expandidos para outros tipos de materiais, sejam de uso geral, sejam de uso específico, por setores profissionais especializados. $\mathrm{O}$ fato é que a Química produziu um ponto de vista próprio acerca dos materiais que pode contribuir para o desenvolvimento da compreensão do mundo.

Seres humanos e químicos, em particular, comunicam-se o tempo todo. Para que haja compreensão mútua das mensagens trocadas entre os interlocutores, é preciso que estes possuam um mínimo de conhecimento comum a respeito do conteúdo e da linguagem na qual as mensagens são elaboradas. O conhecimento da classificação das substâncias químicas amplia o conhecimento acerca dos materiais, assim como atribui mais precisão ao vocabulário dos estudantes, possibilitando-lhes comunicar com outras pessoas e compreender mensagens que, antes, lhes eram inacessíveis.

Com a discussão precedente, pretendemos ter mostrado a contribuição que o ensino da classificação química das substâncias pode trazer para o desenvolvimento intelectual dos estudantes de Química e outras profissões. Dessa forma, são conduzidos a ter uma postura mais crítica ao interagir com os materiais que os cercam e, consequentemente, uma compreensão mais profunda do mundo.

Em termos mais gerais, o ensino do processo de classificação de qualquer conteúdo pode revelar um aspecto de como os seres humanos se constituem enquanto espécie: aquele que se refere a modos de pensar e de falar.

Por fim, reconhecemos a necessidade da realização de pesquisas acerca do ensino e da aprendizagem da classificação química das substâncias, incluindo-se os níveis de desenvolvimento alcançados com sua aprendizagem.

\section{REFERÊNCIAS}

1. Silva, J. L. P. B.; Moradillo, E. F.; Cunha, M. B. M.; Dotto, R. R.; Dourado, P. V.; Anais do VI Encontro Nacional de Pesquisa em Educação em Ciências, Florianópolis, Brasil, 2007.

2. Schummer, J.; Hyle - International Journal for Philosophy of Chemistry 2004, 10, 3 .

3. Schummer, J.; Scientometrics 1997, 39, 107.

4. Feger, H. Em International Encyclopedia of the Social and Behavioral Sciences, Smelser, N. J., Baltes, P. B., eds.; Elsevier: New York, 2001.

5. Ferreira, L. H.; Correa, K. C. S.; Dutra, J. L.; Quim. Nova Esc. 2016, 38, 349.

6. Camel, T. O; Filgueiras, C. A. L.; Quim. Nova 2013, 36, 738; Lefèvre, W.; Found. Chem. 2012, 14, 25.

7. Pazinato, M. S.; Braibante, H. T. S.; Braibante, M. E. F.; Trevisan, M. C.; Silva, G. S.; Quim. Nova Esc. 2012, 34, 21.

8. Özdilek, Z.; Öskan, M.; The Turkish Online Journal of Educational Technology 2009, 8, article 9.

9. Bodé, N. E.; Caron, J.; Flynn, A. B.; Chem. Educ. Res. Pract. 2016, 17, 1156; Silva, F. E. F.; Ribeiro, V. G. P.; Gramosa; N. V.; Mazzetto. S. E.; Quim. Nova Esc. 2017, 39, 329.

10. Santos, S. J.; Ribeiro, M. A. P.; Labarca, M.; Anais do XVIII Encontro Nacional de Ensino de Química, Florianópolis, Brasil, 2016.

11. Atkins, P.; Jones, L.; Laverman, L.; Princípios de Química, $5^{\mathrm{a}}$ ed., Bookman: Porto Alegre, 2018; Brown, T. L; LeMay Jr., H. E.; Bursten, B. E.; Murphy, C. J.; Woodward, P. M.; Stoltzfus, M. W. Química: a ciência central, 13ª ed., Pearson: São Paulo, 2016; Chang, R.; Golsby, K. A.; Química, 11ª ed., AMGH: Porto Alegre, 2013.

12. Brasil. Ministério da Educação. PNLD 2018: Química: Guia de Livros Didáticos - Ensino Médio, Ministério da Educação, Secretaria de Educação Básica: Brasília, 2017.

13. Campos, R. C.; Silva, R. C.; Quim. Nova Esc. 1999, 9, 18; Silva, L. A.; Larentis, A. L.; Caldas, L. A.; Ribeiro, M. G. L.; Almeida, R. V.; Herbst, M. H.; Quim. Nova Esc. 2014, 36, 261.

14. https://dicionario.priberam.org/abstrair, acessada em outubro 2020.

15. Bellas, R. R. D.; Queiroz, I. R. L.; Lima, L. R. F. C.; Silva, J. L. P. B.; Quim. Nova Esc. 2019, 41, 17.

16. Luria, A. R.; Curso de Psicologia Geral, $2^{\text {a }}$ ed., Civilização Brasileira: Rio de Janeiro, 1991.

17. Clary, R.; Wandersee, J.; The Science Teacher 2013, 80, 31.

18. Talanquer, V.; Int. J. Sci. Educ. 2011, 33, 179.

19. Vigotski, L. S.; A Construção do Pensamento e da Linguagem, $2^{\text {a }}$ ed., WMF Martins Fontes: São Paulo, 2009.

20. Eco, U.; Tratado Geral de Semiótica, 4a ed., Perspectiva: São Paulo, 2009.

21. Hardy-Vallée, B.; Que é um Conceito? Parábola: São Paulo, 2013.

22. Bardin, L.; Análise de Conteúdo. Edições 70: Lisboa, 2002.

23. Crosland, M. P.; Historical Studies in the Language of Chemistry, Dover: New York, 2004; Ihde, A. J.; The Development of Modern Chemistry, Dover: New York,1974; Jaffe, B.; Crucibles: the story of chemistry from ancient alchemy to nuclear fission, $4^{\mathrm{a}}$ ed., Dover: New York, 1976; Leicester, H. M.; The Historical Background of Chemistry, Dover: New York, 1956; Maar, J. H.; Uma Pequena História da Química: dos primórdios a Lavoisier, 2a ed., Conceito: Florianópolis, 2008.

24. Lavoisier, A-L.; Tratado Elementar de Química, Madras: São Paulo, 2007; Berzelius, J. J.; Journal de Physique, de Chimie, d'Histoire Naturelle et des Arts (Paris) 1811, 73, 253.

25. Ihde, A. J.; The Development of Modern Chemistry, Dover: New York, 1974.

26. Crosland, M. P.; Historical Studies in the Language of Chemistry, Dover: New York, 2004; Leicester, H. M.; The Historical Background of Chemistry, Dover: New York, 1956; Maar, J. H.; Uma Pequena História 
da Química: dos primórdios a Lavoisier, $2^{\mathrm{a}}$ ed., Conceito: Florianópolis, 2008.

27. Debus, A.; Ciência Hoje 1991, 13, 35.

28. Crosland, M. P.; Historical Studies in the Language of Chemistry, Dover: New York, 2004.

29. Carvalho, R. S.; Sci. Stud. 2012, 10, 759.

30. Berzelius, J. J.; Journal de Physique, de Chimie, d'Histoire Naturelle et des Arts (Paris) 1811, 73, 253.

31. Schummer, J.; Hyle - International Journal for Philosophy of Chemistry 1998, 4, 129.

32. https://iupac.org/what-we-do/periodic-table-of-elements/, acessada em outubro 2020.

33. Scerri, E.; The Periodic table: its history and significance, Oxford University Press: Oxford, 2007.

34. https://goldbook.iupac.org/terms/view/H02889, acessada em outubro 2020.

35. Nomenclature of Inorganic Chemistry: IUPAC Recommendations 2005 (IUPAC Red Book), Connelly, N. G.; Damhus, T.; Hartshorn, R. M.; Hutton. A. T., eds.; RSC Publishing: Cambridge, 2005.

36. Cotton, F. A; Wilkinson, G.; Advanced Inorganic Chemistry: a comprehensive text, $4^{\text {th }}$ ed., John Wiley \& Sons: New York, 1980.
37. Morrison, R. T.; Boyd, R. N.; Organic chemistry, $6^{\text {th }}$ ed., Allyn and Bacon: Boston, 1992.

38. Gonzalez, I. M.; Tese de Doutorado, Universidade Federal da Bahia, Salvador, 2016.

39. Rheinboldt, H.; História da Balança e a Vida de J. J. Berzelius, Nova Stella/Edusp: São Paulo, 1988.

40. Benfey, O. T.; From Vital Forces to Structural Formulas, Houghton Mifflin: Boston, 1964.

41. Maar, J. H.; Revista da Sociedade Brasileira de História da Ciência 1994, 11, 49.

42. https://goldbook.iupac.org/terms/view/S06061, acessada em outubro 2020.

43. https://goldbook.iupac.org/terms/view/F02555, acessada em outubro 2020.

44. https://goldbook.iupac.org/terms/view/H02904, acessada em outubro 2020 .

45. https://goldbook.iupac.org/terms/view/C01022, acessada em outubro 2020 . 